\title{
Intuitions about cases as evidence (for how we should think)
}

\author{
James Andow
}

March 11, 2020

\begin{abstract}
Much recent work on philosophical methodology has focused on whether we should accept EvIDENCE: the claim that philosophers use intuitive judgments about cases as evidence for/against philosophical theories. This paper outlines a new way of thinking about the philosophical method of appealing to cases such that EvIDENCE is true but not as it is typically understood. The idea proposed is that, when philosophers appeal to cases, they are engaged in a project of conceptual engineering and that, within that project, intuitions about cases provide evidence as to the normative constraints which are relevant within that project. The paper demonstrates that this is a feasible interpretation of the way that cases are appealed to in recent journal issues, and makes the case that this would be a better way to think of what philosophers are doing when they appeal to cases.
\end{abstract}

\section{Introduction}

Philosophers often appeal to cases (counterfactual and actual) in their research. Just take a look through a recent issue of a journal. ${ }^{1}$ What are philosophers doing when they appeal to such cases? One common idea is EvIDENCE:

EVIDENCE philosophers use intuitive judgments about cases as evidence for (or against) philosophical theories.

${ }^{1}$ The top three journals in philosophy according to SCIMAGO are Nous, Philosophical Review, and Philosophers Imprint (scimagojr.com). The March 2019 issue of Noûs, October 2018 and January 2019 issues of Philosophical Review, and January 2019 issue of Philosopher's Imprint contain 19 articles. Appeals to cases play a role in all of them. 
Various philosophers have recently raised significant objections to evidence. This paper defends EVIDENCE in light of those objections. However, this paper doesn't defend EviDENCE as it is typically understood.

EVIDENCE is typically understood such that the philosophical theories in question are theories about the nature of either some extant phenomenon or concept. ${ }^{2}$ Here's an example of how that might go in each case.

CAPTURe EXTANT PHENOMENA A philosophical theory about the nature of objects, e.g., might specify necessary and jointly sufficient conditions for being an object. The theory is false if something could meet these conditions and fail to be an object or fail to meet these conditions and yet be an object. Getting information about objecthood in various actual and counterfactual cases is thus a way to get relevant information about whether the theory is true. Such information can be acquired through intuitions. Intuitions about cases provide evidence for/against theories of objecthood.

CAPTURE EXTANT CONCEPTS A philosophical analysis of the concept of vegetarian, e.g., might specify application conditions for the concept of vegetarian such that, if the analysis is correct, the concept applies to something if and only if it meets the relevant conditions. The analysis is wrong if the concept applies in cases that the analysis says it doesn't or doesn't apply in cases the analysis says it does. Getting information about whether the concept of vegetarian applies in various actual and counterfactual cases is thus a way to get relevant information about whether the analysis is correct. Such information can be acquired through the intuitions of concept users. Intuitions about cases provide evidence for/against analyses of concepts.

However, this is not the only way in which eviDEnCE might be understood. The simple reason for this is that philosophers' theorising can have aims other than accurately describing the nature of extant phenomena/concepts.

Philosophers can also engage in conceptual engineering. ${ }^{3}$ As I will use the term for the purposes of this paper, 'conceptual engineering' encompasses all philosophical projects in

${ }^{2}$ Obviously, there are important differences between models of philosophical enquiry that emphasise the analysis of our concepts and those that emphasize discoveries about the extra-mental world. And a full exploration of those models would be important in any fully-developed account of philosophical enquiry. Thanks to a reviewer for making that point. However, for the sake of the current project, the two can be lumped together as being, in some sense, 'descriptive' to be contrasted with the alternative, normative model which the current paper explores.

${ }^{3}$ For an introduction to this concept, see, Cappelen (2018). 'Conceptual engineering' is a loose term used to talk about a family of approaches to philosophical theorising. Plunkett and Cappelen (2020) note in the 
which the aim is to refine our conceptual resources (construed broadly to include, e.g., the introduction of new concepts) such that they meet or come closer to meeting some relevant set of normative standards: standards concerning what our concepts should be like rather than what they are like. The normative constraints operative while conceptual engineering might take many forms: they might be moral, political, theoretical, practical, or arise from some more idiosyncratic preferences. ${ }^{4}$ The important difference between conceptual engineering and the other types of philosophical project outlined above (and typically assumed in discussions of EVIDENCE) is that, when conceptual engineering, philosophical theorising is not purely a descriptive project but a constructive project: in the business of providing a concept that performs as the concept should perform rather than analyzing some extant concept or phenomenon. Within a project of conceptual engineering, evidence that a concept should perform thus-and-so, counts in favour of any proposed conceptual resources that would perform in that way (and against any proposed conceptual resources that would not perform that way). ${ }^{5}$

This paper makes the case for thinking that EVIDENCE is true. This case is both (a) a project in conceptual engineering and (b) a case for thinking of philosophers who appeal to cases as involved in conceptual engineering. It is a project in conceptual engineering insofar as it is proposing a conceptual refinement. The target of the conceptual refinement

introduction to the main collection of work so far on conceptual engineering "We don't think [terms like 'conceptual engineering'] come with fixed meanings. The previous literature has used them in different ways... These terms are often used without precise definitions by those working in the field..." Their own suggested definition is "Conceptual Engineering $=(\mathrm{i})$ The assessment of representational devices, (ii) reflections on and proposal for how to improve representational devices, and (iii) efforts to implement the proposed improvements."

${ }^{4}$ It is worth noting that one key topic in the literature on conceptual engineering concerns what kinds of normative considerations one should pay attention to or should have primacy when conceptual engineering. See Plunkett and Cappelen (2020) for a survey of various types of consideration to which conceptual engineers might appeal in this context. For good discussion and some proposals as to the relevant standards see Cappelen (2018), Simion (2018), and Goetze (fort). See also Cantalamessa (2019)'s discussion of 'conceptual activism' for a different angle. For the sake of the current project, in which I'm thinking about how best to think about extant philosophical practice rather than give a prescriptive account of philosophical methodology, I set aside the issue of what types of standards are legitimately used by conceptual engineers. But, of course, this will be an important issue to address for anyone who wanted to defend the method that I suggest we characterise philosophers as using and I say a little more about that in conclusion.

${ }^{5}$ Alternatively, we could think of a descriptive project as a special case of conceptual engineering, mirroring the difference between NORMATIVE and DESCRIPTIVE in the below: a variety in which the relevant normative constraints are solely in terms of descriptive accuracy, carving nature at its joints, or similar. In fact, I'm not sure that's so terrible a way to think about such things. But the sake of the current project it is helpful to be able to talk of descriptive projects as being distinct from conceptual engineering. Thanks to an anonymous referee for raising the point. 
is the way that we conceptualise the role of intuitions about cases in philosophy. The idea proposed - as a refinement of our ways of thinking about the role of intuitions about casesis that, when philosophers appeal to cases, they are engaged in a project of conceptual engineering and that, within that project, intuitions about cases are used as evidence as to the relevant normative constraints. ${ }^{6}$ As in the traditional model according to which EVIDENCE is true, the proposed model says that intuitions about cases, are used as evidence that serves to constrain what a successful theory will look like. However, according to the proposed model, those constraints (on what a successful theory will look like) are not simply that the nature of some extant phenomenon or concept is accurately described. This is because, the aim of the project within which intuitions about cases are used is not to accurately describe the nature of some extant phenomenon or concept, but to produce a concept that meets some richer set of relevant normative standards. Accordingly, according to the proposed model, the nature of any constraints for which intuitions about cases are used to provide evidence might include other conditions it is thought the concept should meet, e.g., having certain social impacts. ${ }^{7}$

This is a novel proposal, at least insofar as the current discourse stands, about the relation between the method of cases, intuitions, and conceptual engineering. Indeed, the assumption often seems to be that conceptual engineering and the use of intuitions as evidence in philosophy are not natural bedfellows. Here are Plunkett and Cappelen (2020):

\begin{abstract}
Many philosophers think that the so-called method of cases is central to philosophical methodology and that intuitions about cases provide the most important kind of evidence for philosophical theories. One (controversial) way to spell out that view goes as follows: We have a concept, C, and our possession of that concept guides the intuitions about C-related thought experiments. So we can use intuitions about whether someone knows in, say, a Gettier case, as evidence of whether [the concept of knowledge] applies in that case (because the concept somehow guides those intuitions). On this view, intuitions about cases reveal or illuminate core philosophical concepts and that is the reason why the method of cases is central to philosophy.

If, however, your goal is no longer to describe the concepts we have but to improve them to think of how our concepts should be, then it is much less clear that asking questions of the form 'Is this a C?' about an imagined case can serve our purposes. That method, at best, reveals
\end{abstract}

\footnotetext{
${ }^{6}$ This is not the only paper that can be thought of as approaching questions in descriptive philosophical methodology through conceptual engineering. I have done so in other work. For example, in Andow (2015b), I argue we should think about intuitions in a particular way in philosophical methodology given that the exercise should produce 'information that will aid us in formulating practical advice concerning how to do philosophy responsibly/well/better,' and, in Andow (2016), I argue we should think of philosophical methods as being abductive because we should avoid losing sight of why the view that philosophers use intuitions as evidence is prima facie attractive and thinking in this way means we can avoid it.

${ }^{7}$ The idea needn't be that the only role that thinking about cases can play in our intellectual lives is to contribute to a project of conceptual engineering, but simply that this is one of the main things going on when philosophers use cases.
} 
the concepts of $\mathrm{C}$ we as a matter of fact have, but our goal now is to think of what the concept should be.

One way to read this paper is, thus, to give the beginnings of an answer Plunkett and Cappelen's implict question as to how appealing to intuitions about cases could serve the purposes of the conceptual engineer.

It will be helpful to make the nature of the case for EvIDENCE presented in this paper clear.

1. There are only two plausible stories according to which EvIDENCE is true: ${ }^{8}$

NORMATIVE By consulting intuitions about cases we obtain information that places constraints on how we should think about the relevant phenomena and use this to guide our theorising

DESCRIPTIVE As above, but the only information that would place constraints on how we should think is information about the nature of those phenomena or the application conditions of our extant concepts

2. Both NORMATIVE and DesCriptive can give a plausible treatment of a representative sample of cases of philosophers using cases (i.e., we don't need the extra claims in DESCRIPTIVE to give a plausible treatment) (the case for this will be made in $\$ 2$ ).

3. The key costs to EVIDENCE raised in the literature are raised as objections to EVIDENCE as traditionally understood, i.e., as per DESCRIPTIve (these will be presented in $\$ 3$ ), and they don't extend to NORMATIVE (as I develop it) (this case will be made in \$5)

4. There is a significant theoretical cost to abandoning EVIDENCE (this is simply assumed for the sake of this paper). ${ }^{9}$

C. We should think of philosophers use of cases in terms of their using intuitions as evidence for theories (i.e., such that EVIDENCE IS TRUE) along the lines of NORMATIVE (without the additional commitments of DESCRIPTIVE).

\footnotetext{
${ }^{8}$ One exception-a story that wouldn't be included in these two options-that has been put to me is that intuitions could be used simply to evidence how we could think (but not in the context of discovering essences via uncovering modal profiles). I'm not inclined to think that it would be plausible to interpret extant philosophical practice involving cases as doing merely this. But I won't be actively making the case for that claim. In any case, I won't discuss the option further.

${ }^{9}$ The case for this assumption is made elsewhere (Andow, 2020c) and the assumption is widely implicit in the literature on philosophical methodology including among those who deny EVIDENCE. The basic thought is that it is difficult (though of course not impossible) to make sense of why philosophers do what they do with cases in the event that they are not using intuitions about those cases as evidence. If you are not happy with the assumption, feel free to conditionalize the conclusions of the paper.
} 


\section{Philosophers' use of cases can be interpreted as using intuitions as evidence for normative constraints}

This paper makes the case for the claim that when philosophers appeal to cases we should think of them as being engaged in a project of conceptual engineering within which intuitions about those cases are used to provide evidence as to some relevant set of normative constraints. ${ }^{10}$ Is this a plausible way to interpret actual cases in which philosophers use cases? It is even possible to interpret philosophers' use of cases in this way? The purpose of this section is to demonstrate that, in addition to a 'standard' interpretation of philosophers' use of cases, i.e., an interpretation consistent with one of the standard stories about how counterfactual cases involve the use of intuitions as evidence (as per CAPTURE EXTANT PHENOMENA Or CAPTURE EXTANT CONCEPTS in \$1), one can give a plausible reinterpretation on which philosophers' use of cases as engaged in a project of conceptual engineering within which intuitions about those cases provide evidence as to the relevant constraints.

I should make a quick note on the methodology of this section. To make my case, I need to do more than show that one can give a reinterpretation in my terms of a couple of extant cases. This would be rightly unconvincing, as I could have simply cherry-picked a sample that was wildly unrepresentative of the field. So, instead, I have taken steps to ensure some confidence that the sample of cases I look at is (at least) relatively representative of the use of cases in contemporary analytic philosophy. I looked at one recent issue of each of two philosophy journals known for publishing short articles in the analytic tradition. ${ }^{11}$ I selected one case from each article in each of these issues (excepting papers without any obvious appeal to cases). ${ }^{12}$ Many articles contained more than one appeal to a case. In those cases, my selection of examples was guided by which was easiest to explain in isolation. It is worth noting that quite a few of the cases we are about to look at are presented by the relevant author in the context of discussing an argument that the author doesn't themselves endorse.

I anticipate that readers may find some suggested reinterpretations unsatisfying in the following sense: it might be unclear that the project of conceptual engineering suggested

\footnotetext{
${ }^{10}$ I talk about the intuitions providing evidence as to the relevant normative constraints. I can also see a case for talking about the intuitions providing evidence as to what kinds of conceptual resources would meet the relevant normative constraints. It might turn out that there is an important difference between those two ways of talking. But for the sake of this paper, I'll treat those two ways of talking as equivalent.

${ }^{11}$ These were the December 2018 edition of Thought and the January 2019 edition of Analysis.

${ }^{12}$ Clay (2018) is concerned with Aristotle interpretation. Gamester (2018) is concerned with the metaphysics of truth. Iaquinto and Spolaore (2018) is a formally-dense paper on knowledge of acquaintance. Calosi (2018) concerns a tension between various theses in mereology. None of them contains an obvious appeal to cases.
} 
by my interpretative gloss would be a project worth pursuing. ${ }^{13}$ That's possibly a reason to resist my interpretation, if you have a prior commitment to the idea that we should think of philosophers as tending to pursue projects that are worth pursuing. It is certainly a reason to think my interpretation can't straightforwardly be marshalled in defence of the use of intuitions as evidence in philosophy. It would be a defence of thinking of those intuitions having evidential value in a certain project, but the project itself wouldn't be defensible. Although this paper isn't a defence of using intuitions as evidence, I'll make some comments about the extent to which using intuitions as evidence of normative constraints in projects of conceptual engineering might contribute to a project worth pursuing in $\$ 5$.

\title{
Example 1
}

Kauppinen (2018) uses the following case (based on a case in Dougherty, 2015):

\begin{abstract}
Tom thinks we should spend some time doing unpleasant things that help others. This week, he figures he'll have done his bit if he gives up five utils for others. Looking ahead, he thinks each hour spent volunteering at the soup kitchen costs him one util, so he decides to spend five hours there on Saturday. It's just as unpleasant as he thinks. But Tom is future-biased, and regards five hours of past pain as having the same disutility as one hour of future pain. Consequently, when he's about to finish his shift, he realizes that he's after all only suffered one util for others, so his duty calls him to stay another four hours. The next four hours are as unpleasant as he thought, but once they're in the past, he finds that his additional sacrifice amounts to only $4 / 5$ utils, so he'll have to stay yet longer... This sad story keeps repeating itself... Tom's future bias catches him in a Zeno-like situation... This pattern seems irrational.
\end{abstract}

The standard interpretation might be that there are some theories of rationality on the table. These theories make claims that are suppose to hold generally and apply to counterfactual scenarios like this. Some theories, implicated in many common-preferences, allow for the rationality of future bias, e.g., assigning 'a lower disutility to the same amount of pain in the past than in the future.' Some theories condemn future bias as irrational. Kauppinen here rehearses an argument for the latter class of theories using an intuition about the case above as evidence. The expectation is that (absent other considerations) we reject the rationality of Tom's behavior and so reject any account which would classify his behavior in the counterfactual case as rational.

The reinterpretation would be that we think an understanding of rationality shouldn't be such that it applies to folks such as Tom. Not because our extant concept doesn't apply to him. Not because, given the nature of rationality, Tom's pattern isn't rational. But rather because, e.g., we have no use for a concept of rationality which applies to Tom. Thinking

\footnotetext{
${ }^{13}$ For example, you might suspect that although philosophers may use intuitions as evidence of normative constraints those intuitions are not evidence of normative constraints.
} 
about cases like Tom's helps us better understand what we are looking for in such a concept. Our intuitions evidence our theorizing. ${ }^{14}$

\section{Example 2}

Logins (2018) uses the following case (my italics):

Consider an ordinary participant on the famous Let us Make a Deal show... call him Ben... Ben has 'the Monty Hall condition', that is, the condition of being unable to see that it is more probable that the car is behind door 3 than door 1 ... we do not want to say that he possesses the consideration 'it is more likely that the car is behind door 3 than door 1' as a normative reason.

The standard interpretation might be that Login is making a point about possessed normative reasons. Ben wouldn't possess the relevant consideration as a normative reason, we are expected to agree, and so we should reject any view of normative reasons which would have the consequence that Ben would possess the relevant consideration as a normative reason.

The reinterpretation would be that Login is making a point about conceptual refinement. Thinking about cases like Ben's helps us see that we think our conceptual apparatus should distinguish them from other nearby cases. Not because we thereby carve nature at its most important joints. Not because this is the result of an accurate deployment of conceptual resources we already possess. But rather because we find ourselves wanting to mark a distinction; we want conceptual resources that mark a distinction; we think a distinction should be marked. This reinterpretation looks pretty natural given the passage marked in italics.

\section{Example 3}

Abasnezhad and Jenkins (2018) use the following case as part of the setup of their discussion:

Vagueness is associated with ... [s] orites-susceptibility (tolerance to small changes but not to large ones)... Many ordinary objects appear to possess [this feature]. Consider Mount Kili-

\footnotetext{
${ }^{14}$ Note that an intuition about a single case (such as the above) doesn't, of course, make transparent to us some complete sense of the normative constraints relevant to the project in hand. Each intuition provides only a little bit of (likely defeasible) evidence. Note also that the envisaged process of enquiry doesn't go via discovery of the complete set of normative constraints. The idea isn't that philosophers first develop little-by-little an explicitly theory of the relevant normative constraints before developing conceptual resources to meet the constraints. The idea is that philosophical practice of appealing to cases as we know it is tacitly engaged in producing conceptual resources to meet certain normative standards, and that the role of intuitions about cases within that process is to constrain the project of enquiry such that theories arrived at (at least ideally) represent conceptual resources that meet some relevant set of standards.
} 
manjaro.... It also seems tolerant to small changes: if we remove one electron from Mount Kilimanjaro, it does not become a different object. But it is not tolerant to large changes: if we remove all but one of its electrons, we no longer have the same object.

The standard interpretation here might be that we are expected to agree with the judgments about the manipulations of Mount Kilimanjaro and, seeing the truth of those claims, we are supposed to realize something generally true about Mount Kilimanjaro (and similar ordinary objects).

The reinterpretation would be that cases such as these help us recognize certain normative ideas about the relevant concepts. We find out certain facts about how we think our concepts in this vicinity should function. We see that we think it would be a mistake to have concepts that were not tolerant to small changes and yet also that we think it would be a mistake to have concepts that are tolerant to large changes. Now, of course, other normative ideas we have about concepts suggest that there is something troubling about this combination of normative considerations, but nonetheless, these cases help us to see that we think there are these normative constraints. We think removing one electron shouldn't affect whether our concept applies, for example, not because of the content of the concept, or because of the nature of mountains or objects, but because of how we think it should work.

\section{Example 4}

Gregory (2018) uses a contrast between two cases. ${ }^{15}$

Consider the following pair of cases

1. Candice, a meteorologist, is explaining the La Niña weather system to her friend, Cameron. At one point, Cameron says, 'This is interesting'. Cameron is enjoying the impromptu lesson; he does believe that the topic is interesting.

2. Candice, a meteorologist, is explaining the La Niña weather system to her friend, Cameron. At one point, Cameron says, 'This is interesting'. Cameron is not enjoying the impromptu lesson; he does not believe that the topic is interesting.

In Case 1, Cameron makes a sincere assertion: he believes what he says. In Case 2, he makes an insincere assertion. What I wish to suggest is that the quality of Cameron's experience in the two cases would be different. Producing the sincere assertion would feel different from producing the insincere assertion.... the claim I am making is that there is a phenomenological difference between making sincere assertions and making insincere assertions generally.

The standard interpretation might be that there are some theories about the phenomenology of assertion on the table. These theories make claims which are supposed to

\footnotetext{
${ }^{15} \mathrm{He}$ goes on to consider inner speech and the role it may play in self-attributions of belief.
} 
hold generally. Some theories are consistent with the claim that there is a phenomenological difference between making sincere assertions and making insincere assertions generally; some are not. Gregory (2018) presents us with these cases involving Candice, expecting us to agree that the quality of Cameron's experience of asserting in the two cases would be different, and taking himself to have provided us some reason to accept a theory about the phenomenology of assertion that is consistent with the claim that there is a phenomenological difference between making sincere assertions and making insincere assertions generally.

The reinterpretation might be that considering cases such as these helps us to refine our understanding of phenomenology and/or quality of experience. In some important respect the question is - how should we think about those things? There are a whole bunch of similarity relations and differences which might hold between two people's experiential states. Different ways of thinking about what phenomenology is will differ as to which relations are relevant to whether there is a phenomenological difference between those two people's states. When we think about cases like the above, we are exploring not which of those ways of thinking about phenomenology accurately captures what phenomenology is, but rather which way of thinking ought we to have or which does what we want it to do.

\section{Example 5}

Berry (2018) says 'I take it to be fairly intuitive that that there could be mountains in an all gunk world [i.e., a world containing nothing but matter that is infinitely divisible], and then wrangles with a puzzling way in which this conflicts with other intuitive principles.

The standard interpretation here might be that we discover evidence as to the modal profile of concepts like that of mountains by considering such counterfactual cases. Taken alone, this intuitive evidence suggests that our concept of mountains is not rigid or 'twinearthable,' i.e., that it applies to entities with a very different micro-physical structure (although Berry ultimately argues this is not the case).

The reinterpretation might be that consideration of this case provides us with information about what we want from our concepts of things like metaphysical necessity. ${ }^{16}$ What is metaphysically necessary? What is metaphysical necessity? There is no reason we have to think of our intuitions as providing us with information relevant to these questions. What kind of concept of metaphysical necessity have we got a use for? How do we think an understanding of metaphysical necessity should perform? It seems plausible to interpret these as being the kind of questions that our intuitions are helping us to answer.

\footnotetext{
${ }^{16}$ That's more plausible than that Berry is evidencing simply how we should think about mountains.
} 


\title{
Example 6
}

In the context of the discussion of a contingency-based argument for the existence of God, Byerly (2018) is interested in the question of whether a non-theistic explanation of why the necessary being identified in the conclusion of such an argument is necessary (emphasis mine).

\begin{abstract}
...compare a case where you are given an argument for the existence of a black raven, and then wonder why that raven is black. It would not do to be told that it is black because it was identified as the raven in view in the conclusion of an argument for the existence of a black raven. Rather, the sort of explanation you are after might instead say that it is black because all ravens are black (presumably because of something about the internal nature all ravens share in common), or because of some internal features of this particular raven that account for its blackness. The explanation you are after, and appropriately so even if none such proves available, is an explanation in terms of features internal to the object in question.
\end{abstract}

Here the standard interpretation would be that he is wrestling with what counts as a successful explanation. But the passage in italics makes a reinterpretation in my terms rather more appealing.

The reinterpretation would be that this is an exploration of what we want from a concept of explanation. What we discover is the information that a concept of explanation - the one operative when thinking about explanations of universes of contingent things - shouldn't apply in some cases and should apply in others, not because we have discovered facts about the correct application of our concept or about the nature of explanation, but because we have discovered facts about the function that we think a concept of explanation should play.

\section{Example 7}

In the context of a discussion of the metaphysics of color, and an objection to sense data theory, Cutter (2018) considers the following case:

[S] uppose a perceiver - call her Leona - sees an object $o$. In accordance with standard sense data theory, we'll take this situation to involve o's producing, in some non-deviant way, a sense datum in Leona's mind... [S] uppose...o is a tomato seen by Leona in the periphery of her visual field... [and that] $o$ looks red to Leona without looking any determinate shade of red. [Assume that: 'sense data theory is committed to the principle, roughly speaking, that sense data possess all and only the properties that sensibly appear to us.']. [Since]...o looks red to Leona, it follows that the sense datum produced by $o$ is red. [Since]...o doesn't look any determinate shade of red, it follows that the sense datum produced by $o$ does not have any determinate shade of red, thereby violating the [principle that: If $G$ is an n-place determinable, then necessarily, for any $x_{1}, \ldots, x_{n}$, if $G x_{1} \ldots x_{n}$, then there is some determinate $\mathrm{F}$ of $\mathrm{G}$ such that $F x_{1} \ldots x_{n}$ ]. Since this principle is extremely plausible (so the argument goes), we should conclude that sense data theory is false. 
Here there are several supposedly intuitive claims at play. We judge the case to be possible. We judge the principle to be plausible. In any case, the standard interpretation here should be clear. These intuitive claims are supposed to be serving as evidence against sense data theory concerning perception.

The reinterpretation would be that all these intuitive claims are providing us with information about what shape our thinking in this area should look like where that is informed by what we want our thinking in this area to do for us. Some intuitions concern how we should think about certain types of property. Other intuitions concern how we should think about color properties in particular. For example, a way of thinking about colors which does what we want from a way of thinking about colors isn't going to force us to think about all color perceptions as involving things looking determinate shades. Not because of some descriptive facts about phenomenology that we detected by thinking about a counterfactual case. Simply because we don't think it should.

\section{Example 8}

Hedden (2018) provides us with the following case in discussion of hindsight bias. Hindsight bias is 'the phenomenon of being more confident that some body of evidence supports a hypothesis when one knows that the hypothesis is true, than when one doesn't.' In the context of articulating reasons to think hindsight bias can be rational, Hedden (2018) says:

Suppose you're given some true premisses, and you're told that they either entail $H$ or entail $\neg H$. You try to figure out which it is, but with no success (suppose the problem is Fields Medalworthy), so you wind up uncertain about which one is entailed by the premisses. Then, you're told that in fact $H$ is true. Clearly you should conclude that the premisses entail $H$ !

The standard interpretation here would be that intuition tells us that, in such circumstances, one (rationally) should conclude that the premises entail $H$, and since this is a form of hindsight bias, this intuition provides evidence against any theory which renders hindsight bias irrational.

The reinterpretation would be, again, that the philosopher is interested in how we should think about rational norms. Not in what the nature of rationality might be, nor in our extant concept of rationality. Accordingly, what our intuitions tell us is that we are not looking for a way of understanding rationality that produces this verdict.

\section{Example 9}

Reuter et al. (2018) present the results of an experimental study in the philosophy of pain. ${ }^{17}$

${ }^{17}$ In experimental philosophy, it is primarily participants in an survey-based study who have intuitions about 
Here is an example of a case used:

If you were told that somebody had pain in their mouth, how misleading would you consider that statement to be if you were later told that, in fact, the person had pain in their thumb and that their thumb was in their mouth?

The standard interpretation here would be that the issue at stake is the cogency of the so-called 'pain in the mouth' argument from Ned Block, and exploring why it fails, advancing the explanation that the argument fails because the conclusion is misleading in terms of what it implicates. So the immediate theory that the intuitions are speaking to is a theory about which assertions are misleading. The intuitions are evidence as to what is misleading, thus speaking against from theories and in favour of others. Then the facts about what is misleading will help us diagnose an argument and ultimately make progress on the issue of what pain is and what the relation between pain and the apparent bodily location of pain might be.

The reinterpretation would be that what intuitions are ultimately being used as a source of information about is how we should think about the relation between pains and their apparent spatial location. On the way to that issue, facts about what we should think of as being misleading turn out to be relevant, and that's what consulting intuitions about cases is telling us about. The information we get from participants isn't so much information about what they would think was misleading and to what degree, but information about how they think we should think about misleadingness.

\section{Example 10}

Robinson (2018) uses the following case, among a number of others, in other to advance his argument that one can be cruel to an inanimate object. This cases aims to push back against a supposed condition on cruelty: that it is successful in bringing about harm (emphasis mine).

Imagine that Tom is in love with his neighbour. He believes that his neighbour's husband is severely anaphylactic and that peanuts will kill him. Feigning generosity, Tom makes dinner for the couple each week and sprinkles the dish with crushed peanuts. The husband, it so happens, is not actually allergic to peanuts and ends up enjoying the meal even more than he

a hypothetical case, rather than authors and their readers. For an introduction to experimental philosophy see Knobe and Nichols (2017). But there is no obvious reason why the idea of this paper shouldn't extend to any projects in experimental philosophy which some might be tempted to think of as involving the use of intuitions as evidence. Indeed, insofar as there is a perceived methodological continuity between use of cases in traditional philosophy and in experimental philosophy, one might think that any proposed reinterpretation should cover both. 
would have without the peanuts. In the end, good effects are ultimately produced. But I think we can still look at Tom and say that his behaviour is cruel. He intentionally puts peanuts into the meal, hoping to kill the husband and take his wife. But the effects are not 'successful' in the sense that the aims of the motivational component of his act are fulfilled.

The standard interpretation here might be that an intuition about whether this case is cruel speaks in favor of some theories about what cruelty is and against others.

The reinterpretation would be that the author is inviting us to consider the merit in thinking about cruelty in such a way that allows one to say that Tom is cruel. This is suggested by the passage in italics. In either the standard or the novel interpretation, in this case it is natural to read the author as offering only fairly weak evidence - 'there is something going for this way of thinking' rather than 'we should think in this way' which would be stronger.

\section{Example 11}

Finally, Saemi (2018) to make a somewhat involved point about the doctrine of double effect generating the appropriate verdicts about a series of supposed counter-examples, considers the following two cases. I'm going to focus on the second case here (paragraph break mine). ${ }^{18}$

Surely you don't have to call off the [otherwise justifiable bombing] raid just because the only pilot who can successfully carry it out would be killing the children intentionally. But [the doctrine of double effect] is consistent with this. [The doctrine of double effect] has no implication that it is wrong in this case to command the bomber to bomb the factory.

To illustrate, imagine a runaway trolley which will kill five persons unless it's diverted to an alternative track where it will kill a very large person. There is only one office from which the trolley can be diverted, and there is only one switchman who can get to that office in time. The office is located in a way that the switchman can easily see the track with one large person. However, the switchman can see the track with five persons only through a monitor which is currently off. Knowing the facts of the case, you call the switchman asking him to go to the office and turn on the monitor. You also ask him to divert the trolley to the alternative track after he has confirmed that there are five persons on the main track. But you know that the large person on the alternative track is the switchman's lifelong enemy. You also know that as soon as the switchman gets to the office and sees his enemy, without even turning on the monitor and thereby knowing about five persons on the main track, he will divert the switch to murder his enemy. Surely, the switchman acts wrongly in diverting the switch. But [the doctrine of double effect] doesn't imply that you cannot ask him to divert the trolley when he sees five persons on the track.

The standard interpretation here would be that the evidence about what is permissible is consistent in this case (as a member of some salient class of cases) with the doctrine of double effect (against some salient claims to the contrary). The evidence consists in the

${ }^{18}$ The first case is under-described in the excerpt. I included it only because otherwise the purpose of the second case and indeed the intuitive verdict about it would be left cryptically implicit. 
intuition that it is permissible to ask the switchman to divert the trolley when he sees five persons on the track.

The reinterpretation would be that the background debate concerns whether we should think about morality in terms that accommodate the doctrine of double effect, and relevant to that issue is the issue of whether we should think about permissibility in such a way that cases like this come out permissible. Again, thinking as one should isn't simply a matter of getting the facts of permissibility right, or of correctly applying the concept of permissibility, but something else.

\section{Example 12}

Perl (2018) engages with an argument of Parfit's:

\footnotetext{
[Parfit] against Kantian strictures on treating agents as mere means from our intuitions about particular cases.

THIRD EARTHQUAKE You and your child are trapped in slowly collapsing wreckage, which threatens both your lives... [Y] ou cannot save your child's life except by crushing Black's toe, without Black's consent. This act, I believe, would be justified. (Parfit, 2011, 222,231)

Parfit is here appealing to a very familiar kind of evidence: our moral intuitions, our considered moral judgments.
}

The standard interpretation (and one Perl seems to endorse) is that Parfit is using the intuition that crushing Black's toe without Black's consent would be justified as evidence against the theory that it is never justified to treat an agent as a mere means.

The reinterpretation would be that the debate is as to whether we should have a concept of moral justification which takes a certain form. What our intuitive response evidences is that we don't think our way of thinking about moral justification should be such that it never applies in cases of using agents as mere means. It is not necessarily used as evidence of the contours of our extant concept, nor or some actual dividing line between justified and unjustified actions.

\section{Example 13}

Roelofs (2018) engages with an argument from Hutto and Myin (2012, 157-8) which uses the following case to demonstrate that meeting a set of conditions claimed to be sufficient for a cognitive state or process that acts as a surrogate or stand-in for another are not sufficient for that state to have representational content.

Consider a mundane case. Someone, $\mathrm{Y}$, acts as a surrogate for someone else, $\mathrm{X}$, by delegating for X and playing X's role at some function or event. Clearly, even though we might say that $Y$ 
is $\mathrm{X}$ 's representative, it is clear such surrogacy is achieved without $[\mathrm{Y}]$ actually representing $[\mathrm{X}]$ in any contentful sense. We can also assume that in order to play the surrogacy role on some occasion, it is further required that $\mathrm{Y}$ structurally resembles $\mathrm{X}$. Perhaps $\mathrm{Y}$ needs to structurally resemble $\mathrm{X}$ in several respects at once. Allow that some of these respects are quite abstract, such as sharing X's height or X's capacity for witty repartee. Even in such cases Y does not represent $\mathrm{X}$ in any contentful sense. As it is with one person acting as a surrogate or stand-in for another, so it is with a cognitive state or process that acts as a surrogate or stand-in for another.

The standard interpretation might be that intuitions about whether a person in such circumstances represents another in a contentful sense are being used as evidence as to whether they do, which is in turn used as evidence against certain theories of what it is to contentfully represent.

The reinterpretation would be that this is part of a negotiation of trying to work out what kind of concept of representation we should have. What we discover by considering this case is evidence for certain constraints in that project: we want a concept of having representational content for cognitive states which will maintain certain analogies with our ways of thinking about similar phenomena, and we don't want to think about people who act as a surrogate for another representing them in a contentful sense.

\section{Example 14}

Simchen (2018) considers a classic case from which is used to draw out what seems to be a feature of Frege's theory of indirect reference: the apparent infinite hierarchy of senses. This feature is typically taken to be a negative feature. The argument in which the case is embedded are expressed over quite a long passage in the target article and can't be easily, sensibly excerpted. But it can be summarised as follows. Burge first argues against a thesis 'Sense collapse' using a reductio. Simchen uses the following notation: "For any expression $\alpha$, let " $S \alpha{ }^{S}$ ' refer to the sense of $\alpha$." Sense collapse is then the thesis that ${ }^{S S} \alpha^{S S}={ }^{S} \alpha^{S}$. Burge shows that assuming this leads to contradiction using the case of embedding 'Opus 132 is a masterpiece' in the contexts 'Bela believes Opus 132 is a masterpiece' and 'Igor believes Bela believes Opus 132 is a masterpiece'. But if this generalizes, and for any $\alpha,{ }^{S S} \alpha^{S S} \neq{ }^{S} \alpha^{S}$, an infinite hierarchy of senses seems to follow, and, as Burge puts it, 'An infinite hierarchy of entities is, I suppose, theoretically unappealing other things being equal' (p.274).

The standard interpretation seems to be as follows: that it has an unintuitive consequence is evidence against Fregean doctrine.

The reinterpretation could be simply that by thinking about this case and the implications of thinking about this case in various ways we discover evidence concerning certain normative constraints - our thinking about language and meaning and embedding ought not commit us to infinite hierarchies in this way. It is not evidence as to the nature of the 
phenomenon, meaning, or evidencing the structure of our extant conceptual apparatus for thinking about such things, rather we discover something we take to be a theoretical cost in another way or more general way: we don't want a way of thinking about meaning that performs in this way.

\section{The key arguments against EVIDENCE}

We've seen that one can give a plausible reinterpretation of what philosophers are doing when they appeal to cases using NORMative. So, we can think of evidence being true as understood along the lines of Normative. But should we?

Suppose we had serious reasons to resist an understanding of philosophical methods that said we consult intuitions about cases and thereby get evidence about metaphysical natures or about extant concepts. In that event, it seems the way we should think about the role of intuitions about cases in philosophy should reject DESCRIPTIVE; since we can think of philosophers use of cases along the lines of NORMATive, and since we don't want to reject EVIDENCE without a very good reason (assumed for the sake of this paper), in the event we had serious reasons to doubt DESCRIPTIVE seems that we should accept nORMATIVE. So long, that is, that the serious reasons to resist DESCRIPTIVe didn't extend to NORMative.

Do we have serious reasons to doubt DESCRIPTIVE (the typical understanding of eVIDENCE)? Various folks have argued that we do (notably Cappelen 2012, but see Nado, 2016, for more summaries and citations). So first, let's review those arguments. Following Nado (2016), we can identify three main reasons people have given for resisting the picture according to which philosophers use intuitions as evidence.

ARGUMENT FROM UNCLEAR APPLICATION What is an intuition anyway? There is no clear and widely agreed characterisation of intuition among philosophers. Since we can't even work out what intuitions are supposed to be and philosophers vary wildly in their understanding of what intuitions are, it seems unlikely that relying on intuitions as evidence is a key part of the philosophical methodology. Certainly, the theory that philosophers use intuitions as evidence in philosophy is not a helpful or informative theory - not one we should accept.

ARgUment From anti-PSYCHOlogism Philosophers don't 'psychologise' their evidence. A proper understanding of philosophical arguments and the logical structure of philosophical enquiry holds that our evidence consists in propositions about knowledge, morality, freedom, and so on, and not about what we find intuitive about those things. And, more importantly, philosophical practice conforms to this 
understanding: philosophers rarely explicitly couch their premises in psychological terms.

ARGUMENT FROM ARGUMENTATION If we examine the evidence (texts in which appear supposedly paradigmatic instances of intuitions being used as evidence by philosophers), we find that the supposedly intuitive claims are backed up with arguments like any other claim. You wouldn't expect to find that if philosophers were using the intuitions as a basic source of evidence, having any special epistemic status, or similar.

These concerns represent the main serious theoretical costs to accepting DESCRIPTIVE (and so EVIDENCE as typically understood). But, so long as these concern don't extend to NORmative, the case for my conclusion is complete. Demonstrating that the three arguments don't extend to normative is thus the next important step in my argument. First, however, it will be useful to have a richer understanding of what it might mean to use intuitions as evidence as to normative constraints within a project of conceptual engineering, and to do that a little digression is helpful.

\section{A richer model of using intuitions as evidence of nor- mative constraints}

An important distinction There are two distinct questions in philosophical methodology: (1) What methods do philosophers use?, and (2) Should philosophers use those methods? The answers need not paint a positive picture of current philosophical methods. It is possible that the best way of thinking about the methods that philosophers actually use attributes to them the use of a method which we shouldn't endorse.

This paper is interested only in making the case for the following claim: We should think of philosophers use of cases in terms of their using intuitions as evidence for theories (i.e., such that evidence is true) along the lines of normative (without the additional commitments of DESCRIPTIVE). So, this paper should not be interpreted as making the case for that method, but only as presenting some reasons to think philosophers use such a method. The main task of the rest of the paper is to demonstrate that the key objections to EVIDENCE in the literature apply only to Descriptive and not to normative (as I will develop it).

However, although strictly orthogonal to the aims this paper, it is helpful at this stage to briefly reflect on whether using intuitions as evidence for normative constraints in a project of conceptual engineering would be remotely defensible as a philosophical method. This 
reflection will help flesh out our understanding of what it might mean to use intuitions as evidence as to normative constraints within a project of conceptual engineering, and, in turn, will help us to see how objections to DESCRIPTIVE needn't extend to NORMATIVE.

Doubt about whether philosophers should endorse such a method It is easy to see why someone might have their doubts. We can present the thought in the shape of a cartoonish objection. This cartoonish objections attempts to force the proponent of the method onto a dilemma.

1. We should only endorse methods the use of which would be both (a) not pointless, i.e., one would stand a decent chance of achieving the ambitions of one's research, and (b) worthwhile.

2. There are only two types of normative constraint that intuitions might be used as evidence for within a project of conceptual engineering:

SUBJECTIVE constraints grounded in idiosyncratic whim, e.g., if you want a concept of $\mathrm{X}$ that does such-and-such, then...

OBJECTIVE constraints represented by some objective, quasi-moral, mindindependent standards that concepts of $\mathrm{X}$ should live up to

3. Conceptual engineering in which the constraints are merely SUBJECTIVE is not worthwhile. ${ }^{19}$

4. Conceptual engineering in which the constraints are OBJECTIVE and intuitions are used as evidence as to those constraints is pointless (as it is unclear why we should have any faith that our intuitions put us in contact with such constraints). ${ }^{20}$

\footnotetext{
${ }^{19}$ The thought might be that such a practice would face a charge of unacceptable parochialism along the lines that Machery (2017) thinks faces a philosophical project which, having accepted that different people operate with different sets of conceptual resources, decides that the philosophically interesting target of investigation is the conceptual resources that the investigators happen to possess. We have a sense that philosophy should aspire to more than this. We have a sense that if philosophy is in the business of conceptual engineering then the normative standards to which conceptual innovations or refinements should aspire are on a rather grander scale: conforming to some single set of objective standards for good conceptual resources, working to promote justice, or similar.

${ }^{20}$ The thought might be that such a practice will face a charge similar to that of unacceptable dogmatism that Machery (2017) thinks faces a philosophical project which, aspiring to the universal, relies on one's own intuitions (or the intuitions of a small relatively homogeneous group) having accepted that there is widespread interpersonal variation in intuitions. It could seem especially arrogant to think that one's own intuitions from the armchair were capable of putting one in contact with the objective standards for how philosophically interesting phenomena should be thought about.
} 
5. Using intuitions as evidence as to constraints within projects of conceptual engineering is either to conduct pointless research or research which is not worthwhile. (from $2,3,4)$

C. We should not endorse using intuitions as evidence as to the normative constraints within projects of conceptual engineering. (from 1, 5)

How might a proponent of the method respond? To defend the relevant method, it would be important to demonstrate that there is a middle-ground: constraints which intuitions do plausibly put us in contact with and that it would be worthwhile working within. I'm not going to do their work for them. However, thinking about what constraints a proponent of such a practice might appeal to - what kind of constraints plausibly occupy this middle ground - helps to flesh out our understanding of what it might mean to use such a method, and, in turn, will help us to see how objections to DESCRIPTIVE needn't extend to NORMATIVE (i.e., the main point of this section).

What type of constraint might plausibly occupy this middle-ground? One type of constraint that seems to fit the bill is standards which arise from the preferences and dispositions of humans or perhaps of some non-arbitrary important group of humans (e.g., citizens of liberal democracies, women, climate refugees, the working classes). Producing conceptual resources to meet such constraints seems plausibly philosophically worthwhile. Moreover, it is plausible that people's intuitive responses to cases (or, at least, those of members of relevant groups, or representative members) provide utilizable evidence as to the nature of such constraints. ${ }^{21}$ Even constraints grounded in more localised human concerns seem to fit the bill, e.g., constraints within a project in philosophy of biology that are grounded in current dialectical dynamics within the biological sciences. These seem like they might constrain worthwhile research, and that the research could be conducted using the intuitive judgement about cases of those familiar with the relevant field as evidence as to such constraints.

\footnotetext{
${ }^{21}$ It might be that, if this is what philosophers are doing - working within such constraints, then there is a good case to be made against traditional use of intuitions about cases (i.e., an individual in an armchair), and in favour of empirical approaches (e.g., large scale empirical investigation of intuitive responses to cases). That discussion is orthogonal to my aims here. But, I should note that, were I to endorse the method under discussion, I'd be very comfortable with this conclusion (see, Andow 2020a). For more discussion of potentially mutually-beneficial ways that conceptual engineering and empirical work, e.g., experimental philosophy, could work together see Fisher (2015); Justus (2012); Koch (2019); Lindauer (2019); Machery (2017); Nado (2019); Pinder (2019); Schupbach (2015); Shepherd and Justus (2015); Torregrossa (ms).
} 
Clarifying the descriptive picture I make the case for thinking of philosophers as using intuitions as evidence as to the normative constraints within conceptual engineering projects when they appeal to cases. We now have a better sense of what that would mean. The kind of constraints that the practice of consulting intuitions about cases might plausibly provide philosophers with evidence of are constraints that are grounded in human preferences and dispositions (whether globally or more locally). One clarification of this model of philosophical practice is important. The claim is not that philosophers conceive of themselves as engaged in such a practice but that it is what they are doing (whether or not they conceive of their practice in this way). Indeed, I'm pretty sure most philosophers don't think of their work in this way. On the picture of philosophical methods I suggest we adopt, many or most philosophers are unknowing conceptual engineers.

This is not an eccentric proposal. Plunkett and Cappelen (2020) raise the prospect that conceptual engineering might work in this way when they ask whether it might be best if conceptual engineering were done this way:

\begin{abstract}
how much does one need to be aware of doing conceptual engineering to count as doing it?... how much does one need to be aware of doing it in order to do it well? Is explicit engagement with conceptual engineering always better than implicit engagement with it? For example, perhaps the best methodology for pursuing conceptual engineering (at least in certain kinds of inquiry) is not to focus on conceptual engineering as such, but rather just engage in ongoing inquiry into the intuitively relevant subject matter and then just let conceptual evolution happen naturally as part of the process
\end{abstract}

Indeed, the idea that philosophers might be mistaken about (or have an incomplete view of) what they are doing shouldn't be too surprising. It is a commonplace among philosophical methodologists that the best account might depart from philosophers' self-conception. Just as, in philosophy of science, we might think scientists themselves don't fully understand how their disciplines work, e.g., they might endorse a Popperian model which isn't the best way to capture the nature of their methods. Indeed, we've already encountered those philosophical methodologists who argue against traditional construals of EvIDENCE, i.e., they argue that all those philosophers that think of themselves as frequently relying on intuitions as evidence don't do anything of the kind. ${ }^{22}$

Nonetheless, I do recognise that some think that the only appropriate subject matter for philosophical methodology is methods which philosophers would recognise themselves as

\footnotetext{
${ }^{22}$ Anecdotally, this seems to be a lot of philosophers. And, although it is a slightly different question, one survey found that $57 \%$ of philosophers think intuitions are helpful for discovery in philosophy and even that over 30\% think that intuitions are essential (Kuntz and Kuntz, 2011). And I've recently replicated those results (Andow, 2020b). But if those who argue against EviDENCE are right, then it is only when in a metaphilosophical mode that philosophers have a tendency to think of themselves as using intuitions as evidence.
} 
following. I disagree, as have many others (see, e.g., Loeb, 2016). A study of philosophical methods can also be a study of the structure of philosophical practice, argument, discussion, change, publishing, and so on, at a more causal/sociological level. ${ }^{23}$ The model proposed in this paper should be understood in a similar way. The model is not a model of what is going on inside philosophers' heads but of the structure of their practice. The proposal is that, whether or not philosophers themselves think of their practice in this way, we should think of the structure of philosophers' appeals to intuitions about cases being such that the intuitions serve to constrain philosophers' attempts to produce new ways of thinking, that is, their use helps establish normative constraints on ways of thinking in the relevant domain.

\section{Objections to DESCRIPTIVE don't extend}

We are now in a position to assess whether the standard objections to EvIDENCE apply only to DESCRIPTIVe but would also extend to NORMative and, in particular, the richer understanding of how such a model might work outlined in the previous section.

ARGUMENT FROM UNCLEAR APPLICATION What even is an intuition? The concern was that since we can't even work out what intuitions are supposed to be and philosophers vary wildly in their understanding of what intuitions are, it seems unlikely that relying on intuitions as evidence is a key part of the philosophical methodology. Certainly, the theory that philosophers use intuitions as evidence in philosophy is not a helpful or informative theory - not one we should accept - insofar as what is meant by 'intuitions' is so unclear.

However, the model under consideration suggests a clear account of intuitions. The model suggest that the 'intuitions' that the model claims are used as evidence for normative constraints when philosophers appeal to cases are something to do desires/preferences. There is some wiggle room as to exactly what sort of states should be the focus of the model. Perhaps those intuitions simply are (perhaps latent) desires/preferences. Or, more likely, perhaps they are occurrent states elicited by cases that are either expressive or indicative of such desires/preferences. Beyond that, the model can be happy to accept that the relevant mental states comprise something of a hodge-podge heterogeneous class. Nonetheless, the model under consideration can be clear about the kinds of states it concerns. Moreover, because, on the proposed model, we are talking about features of philosophers' practice of which they themselves are not aware, the fact that philosophers haven't a broadly agreed upon conception of intuitions shouldn't worry us unduly.

${ }^{23}$ See, e.g., Andow (2015a); Ashton and Mizrahi (2017); Bourget and Chalmers (2014); Bruya (2015); Collins (1998); Healy (2015); Kuntz and Kuntz (2011); Noichl (2019); Weingart (2015); Weisberg (2017). 
ARGUMENT FROM ARGUMENTATION Why do philosophers argue for the 'intuitions' they are supposedly using as evidence? This concern was based on an empirical examination of the source texts in which a bunch of paradigm examples of 'using intuitions as evidence' are presented. ${ }^{24}$

Why would philosophers present arguments for intuitions which are being used as evidence of normative constraints? One reason could be simply that desires and preferences can be obscure to the subject, and so one may need to help interlocutors recognise a shared desire. Another reason can be to help interlocutors appreciate the richer details of a shared intuitive response and so is more informative about the relevant normative constraints. That needs a little unpacking and it is helpful to consider an example.

Take one of the examples that Cappelen uses to presenting his version of the ARGUMENT FROM ARGUMENTATION. Cappelen's clearest example of a supposedly paradigm instance of a philosopher using an intuition as evidence but in which the philosopher immediately presents an argument for the intuitive claim—treating it as in need of justification-is that of Lehrer (2000)'s Truetemp case (Cappelen, 2012, 167-8).

Here is Lehrer's initial setup:

\begin{abstract}
Suppose a person, whom we shall name Mr. Truetemp, undergoes brain surgery by an experimental surgeon who invents a small device which is both a very accurate thermometer and a computational device capable of generating thoughts. The device, call it a tempucomp, is implanted in Truetemp's head so that the very tip of the device, no larger than the head of a pin, sits unnoticed on his scalp and acts as a sensor to transmit information about the temperature to the computational system of his brain. This device, in turn, sends a message to his brain causing him to think of the temperature recorded by the external sensor. Assume that the tempucomp is very reliable, and so his thoughts are correct temperature thoughts. All told, this is a reliable belief-forming process. Now imagine, finally, that he has no idea that the tempucomp has been inserted (p.168) in his brain, is only slightly puzzled about why he thinks so obsessively about the temperature, but never checks a thermometer to determine whether these thoughts about the temperature are correct. He accepts them unreflectively, another effect of the tempucomp. Thus, he thinks and accepts that the temperature is 104 degrees. It is. Does he know that it is? (p. 187)
\end{abstract}

...Does Lehrer's reply to his question, "Does he know that it is?," fit the model...?... The answer... is an unequivocal 'no'. The first thing Lehrer does after asking the question, "Does he know that it is?," is to present several arguments for responding with 'No.' The primary argument goes something like this: "More than possession of correct information is required for knowledge. One must have some way of knowing that the information is correct" (p. 188). Since Mr. Truetemp has no way of knowing that the information is correct, he doesn't know. In the text, the negative answer to the question, "Does he know that it is?," is derived from

\footnotetext{
${ }^{24}$ In fact, I'd be interested to see a more systematic investigation than Cappelen (2012)'s. In the cases I looked at above, this feature is rather less obvious - perhaps because the cases are somewhat dialectically embedded, e.g., presented in the context of discussing an opponent's argument.
} 
this more general principle. So the answer is not presented as a basic, unjustified but justifying starting point in argumentation.

Our question is: Why would Lehrer do this if he was using intuitive response to $\mathrm{Mr}$ Truetemp as evidence as to the relevant normative constraints on the conceptual engineering project concerning our epistemic concepts? Suppose that a reader's awareness of their intuitive response to the case is simply that they have a negative reaction to applying the concept of knowledge to Truetemp. The information that this 'bare' intuitive response can provide as to some relevant set of normative constraints is comparatively meagre. The intuition might evidence normative constraints that say a concept of knowledge shouldn't apply to Mr Truetemp. But that isn't a very rich characterisation of the relevant normative constraints. By offering considerations in favour of the verdict about the case, Lehrer is bringing to our attention the richer aspects of what is assumed to be a common intuitive reaction to the case, and those richer aspects provide richer information about the relevant constraints, e.g, that what we want from a concept of knowledge is not the mere tracking of those who possess correct information.

ARGUMENT FROM ANTI-PSYCHOLOGISM Why don't philosophers explicitly couch their premises in psychologised terms? The concern here was that it would seem like a mistake for philosophers to treat their evidence as consisting merely in claims about our psychology, e.g., 〈intuitively Truetemp doesn't know〉, rather than about knowledge itself, e.g., 〈Truetemp doesn't know〉, but more importantly that there is little evidence of philosophers actually psychologising their evidence in this way. Philosophers rarely explicitly couch their premises in psychologised terms; when they use do words like 'intuitively' this can typically be understood as a mere hedge.

Why don't we state our premises in this way? Because, according to the proposed model, we're typically not aware of the nature of our practice, we don't explicitly conceive of ourselves as engaged in conceptual engineering, engaged in theory construction which is sensitive to normative constraints grounded in psychological states. The idea is that philosophers are building the conceptual resources we should have and are guided in that project by their intuitive responses to cases. The idea is not that philosophers are explicitly reasoning from premises about intuitive responses to conclusions about what concepts we should use. 


\section{Conclusion}

What are philosophers doing when they appeal to cases? I made the case for a commonly held idea-that philosophers are using intuitions about cases as evidence-but not as it is typically understood. I made the case that we think of philosophers using cases as conceptual engineers gathering evidence as to the normative constraints for their projects on the basis that this is a way to avoid the theoretical costs of abandoning the claim that philosophers use intuitions about cases as evidence while having the resources to resist recent arguments against that claim.

The paper made three key moves in its case for that position. The first move was to recognise that there is more than one way of the claim that philosophers use intuitions as evidence being true. There is the traditional model according to which philosophers are trying to construct theories that accurately capture the structure of some phenomenon in the world or the structure of our extant concepts and that their use of cases involves using intuitions about those cases as evidence as to those things. And then there is my proposed model according to which philosophers are conceptual engineers constructing conceptual resources that do what they should do and that their use of cases involves the use of intuitions about those cases as evidence as to the relevant normative constraints within those projects. The second move was to demonstrate that my proposed model can make sense of a representative sample of philosophers using cases within contemporary analytic philosophy. The third move was to show that the proposed model has the resources to resist recent arguments against the claim that philosophers use intuitions about cases as evidence.

To avoid confusion, I should reiterate that, while I advocate interpreting philosophers as using intuitions as evidence within conceptual engineering projects, I have not defended using intuitions as evidence within conceptual engineering projects. ${ }^{25}$ However, if we did adopt the suggested understanding of philosophers' use of cases, it would be very important to examine the merits or problems with what philosophers are doing with cases. While I won't conduct that examination here, I will finish by noting a few key challenges that will faced by anyone who wants to defend philosophers' appeals to cases given my suggested understanding of the practice. One thing these challenges serve to highlight is that anyone

${ }^{25}$ The closest I got to defending such a method has been to (a) raise the question as to whether such a method is remotely defensible, and (b) express the opinion that using such a method isn't obviously indefensible in principle. The case for such a method not being completely indefensible was that it is plausible that intuitions about cases might put us in touch with normative constraints that could be used in a worthwhile philosophical project of conceptual engineering if the relevant constraints were grounded in the preferences and dispositions of groups to which the people having the intuitions belong (and presumably are representative in some respect). 
who wanted to defend philosophers' use of cases - given an understanding of those philosophers as using intuitions about cases as evidence for normative constraints within a project of conceptual engineering - would have to have clear idea about what kind of conceptual engineering they thought philosophers were engaging in (or what 'theory of conceptual engineering' they endorsed).

A first challenge, for anyone who wanted to defend philosophers' appeals to cases (interpreted as I suggest), is that they would have to defend the relevant method in practice and not just in principle. I made the case that it is plausible to interpret philosophers' actual appeals to cases as as being engaged in a project of conceptual engineering within which intuitions about those cases are used to provide evidence as to some relevant set of normative constraints (see $\$ 2$ ). I also made the case that such a method does, in principle, seem to be remotely defensible in instances where intuitions evidence normative constraints grounded in the preferences and dispositions of groups to which the people having the intuitions belong (see $\$ 4$ ). But I didn’t link those two cases up. That is to say, I didn't argue that it is remotely defensible to interpret philosophers' actual appeals to cases as having those further features. So, to defend philosophers methods, as I suggest we understand them, will require at least either (i) linking things up and defending an interpretation philosophers' actual appeals to cases as having the further features (which I suggested might make the method remotely defensible), or (ii) providing some other favourable interpretation according to which philosophers are not only conceptual engineering but are doing it correctly/well.

A second challenge, for anyone who wanted to defend philosophers' appeals to cases (interpreted as I suggest), is that they would have to respond effectively to various extant challenges to the use of intuitions as evidence in philosophy. At least at first glance, for example, any challenges concerning the reliability of intuitions given demographic differences and framing effects (for relevant discussion, see, e.g., Feltz and Cokely, 2012, 2016; Hannikainen et al., 2018; Knobe, 2019; Machery, 2017; Machery and Stich, 2019; Wiegmann and Waldmann, 2014) seem like they would be no less cogent as applied to the relevant method (than applied to the use of intuitions understood as providing as evidence about extant concepts or phenomena à la DESCRIPTIVE). So, it would be important that anyone who wanted to defend philosophers' appeals to cases (interpreted as I suggest) were able top defend the claim that intuitions about cases are reliable indicators of the relevant normative constraints despite any evidence of interpersonal and intrapersonal variability. ${ }^{26}$

\footnotetext{
${ }^{26}$ Interestingly, debate over this kind of reliability seems likely to raise rather different issues than familiar debates about the reliability of intuitions vis-a-vis the truth of their propositional contents (e.g., whether intuitions are the product of something like conceptual competence, or even expertise, seems potentially to be less important).
} 
A third challenge, for anyone who wanted to defend philosophers' appeals to cases (interpreted as I suggest), is that they would have to respond effectively to any relevant concerns raised within the literature on conceptual engineering. Two general level concerns spring to mind. (1) One general concern facing conceptual engineers involves worries about metasemantic externalism meaning we have little control over what our terms mean (see Cappelen, 2018, and see Pinder forthcoming, Riggs forthcoming and Koch forthcoming for some recent critical discussion). So, anyone wanting to defend the practice of using intuitions about cases as evidence of normative constraints within a (typically implicit) practice of conceptual engineering, would have to have an adequate story about how meaningful conceptual change is possible. (2) One general concern facing conceptual engineers is as to what kinds of normative consideration can play a legitimate role in conceptual engineering. While some in the conceptual engineering literature have argued for fairly restrictive accounts of conceptual engineering in this regard, e.g., that semantic or epistemic considerations must be primary (notably Cappelen, 2018; Simion, 2018), it seems plausible to think intuitions about cases would be guided by many kinds of consideration without, necessarily, a primary role tending to be given to semantic or epistemic considerations, e.g., ethical and pragmatic considerations. So, it would be important for the defender of the method in practice to say more about (a) what kind of normative constraints they think actually guide the conceptual engineering in which appeal to cases plays a role, and (b) about the legitimacy of conceptual engineering which is guided by such constraints.

Finally, related to the issues raised above, there are also more specific concerns that may be relevant depending on the precise model of 'intuitions evidencing constraints within conceptual engineering projects' one chose to defend. For example, consider that a number of the reinterpretations I suggested (see $\$ 2$ ) of actual instances of philosophers' appeals to cases make use of ideas such as 'what a concept should do for us' or 'what function it should have.' Such phrases suggest an interpretation of the relevant philosophers as conceptual engineering along the lines of function-based understandings of conceptual engineering (such as Cappelen 2018 identifies with Brigandt 2010; Haslanger 2000; Thomasson 2020, and see also Nado 2019; Prinzing 2018). While function-based understandings of conceptual engineering are popular, there are some challenges to the tenability and value of such projects to be met in relation to concerns about the central notion of the function of a concept (Cappelen, 2018). ${ }^{27}$ Answers to questions like 'How do you identity which of the various uses to which a concept can be and is put indicates its function?', for example, are a little

${ }^{27}$ Alternatives include Cappelen's own 'Austerity framework' or a conception that casts conceptual engineering as meta-linguistic negotiation. 
difficult to answer convincingly. But anyone who wanted to defend such a method (similar to the one attributed to philosophers by the kind of reinterpretation I offered) seems to require compelling answers to such questions. The more general model I sketched in the above (in $\$ 4$ ) - which paints a picture of philosophers engaged in normative conceptual enquiry in which the relevant constraints arise from the preferences and dispositions of some relevant population - wouldn't face exactly the same difficult questions. But it would face related concerns. And questions such as 'How do you identify which preferences and dispositions give rise to norms that constrain worthwhile conceptual engineering projects?' are similarly not straightforward to answer.

So, in short, in proposing that we understand philosophers as using intuitions about cases as evidence within projects of (implicit) conceptual engineering, I do not take myself to be contributing to a defence of philosophers' use of cases. Maybe such a model will ultimately help the defender of this aspect of philosophical methods, but they'll have to do a lot of work first.

\section{References}

Abasnezhad, A. and C. S. I. Jenkins (2018, December). Metaphysical vagueness without vague objects. Thought: A Journal of Philosophy 7(4), 278-283.

Andow, J. (2015a). How ‘intuition’ exploded. Metaphilosophy 46(2), 189-212.

Andow, J. (2015b). Thin, fine and with sensitivity: A metamethodology of intuitions. Review of Philosophy and Psychology, 1-21.

Andow, J. (2016). Abduction by philosophers: Reorienting philosophical methodology. Metaphilosophy 47(3), 353-370.

Andow, J. (2020a). Fully experimental conceptual engineering. Under review.

Andow, J. (2020b). How do philosophers and nonphilosophers think about philosophy? and does personality make a difference? In preparation.

Andow, J. (2020c). If philosophers aren't using intuitions as evidence, what are they doing? Under Review.

Ashton, Z. and M. Mizrahi (2017, Jun). Intuition talk is not methodologically cheap: Empirically testing the "received wisdom" about armchair philosophy. Erkenntnis. 
Berry, S. E. (2018, May). Gunk mountains: A puzzle. analysis 79(1), 3-10.

Bourget, D. and D. J. Chalmers (2014, September). What do philosophers believe? Philosophical Studies 170(3), 465-500.

Brigandt, I. (2010, November). The epistemic goal of a concept: accounting for the rationality of semantic change and variation. Synthese 177(1), 19-40.

Bruya, B. (2015, October). Appearance and reality in the philosophical gourmet report: Why the discrepancy matters to the profession of philosophy. Metaphilosophy 46(4-5), 657-690.

Byerly, T. R. (2018, June). From a necessary being to a perfect being. analysis 79(1), 10-17.

Calosi, C. (2018, December). Solving a mereological puzzle. Thought: A Journal of Philosophy 7(4), 271-277.

Cantalamessa, E. A. (2019, August). Disability studies, conceptual engineering, and conceptual activism. Inquiry, 1-30.

Cappelen, H. (2012). Philosophy Without Intuitions. OUP.

Cappelen, H. (2018). Fixing Language: An Essay on Conceptual Engineering. Oxford: Oxford University Press.

Clay, G. (2018, October). Aristotle's argument from truth in metaphysics $\gamma$ 4. analysis 79(1), 17-24.

Collins, R. (1998). The sociology of philosophies: A global theory of intellectual change. Harvard University Press.

Cutter, B. (2018, June). Indeterminate perception and colour relationism. analysis 79(1), 25-34.

Dougherty, T. (2015, DEC). Future-Bias and Practical Reason. PHILOSOPHERS IMPRINT 15(30), 1-16.

Feltz, A. and E. Cokely (2012). The philosophical personality argument. Philosophical Studies 161(2), 227-246.

Feltz, A. and E. T. Cokely (2016, April). Personality and philosophical bias. pp. -. 
Fisher, J. C. (2015, April). Pragmatic experimental philosophy. Philosophical Psychology 28(3), 412-433.

Gamester, W. (2018, February). Logic, logical form and the disunity of truth. analysis 79(1), $34-43$.

Goetze, T. S. (fort). Conceptual responsibility. Inquiry: An Interdisciplinary Journal of Philosophy.

Gregory, D. (2018, December). The feeling of sincerity: Inner speech and the phenomenology of assertion. Thought: A Journal of Philosophy 7(4), 225-236.

Hannikainen, I. R., E. Machery, and F. A. Cushman (2018). Is utilitarian sacrifice becoming more morally permissible? Cognition 170, 95-101.

Haslanger, S. (2000). What good are our intuitions: Philosophical analysis and social kinds. Aristotelian Society Supplementary Volume 80(1).

Healy, K. (2015). Gender and citation in four general-interest philosophy journals, 19932013.

Hedden, B. (2018, June). Hindsight bias is not a bias. analysis 79(1), 43-52.

Hutto, D. D. and E. Myin (2012). Radicalizing enactivism: Basic minds without content. MIT press.

Iaquinto, S. and G. Spolaore (2018, June). Outline of a logic of knowledge of acquaintance. analysis 79(1), 52-61.

Justus, J. (2012). Carnap on concept determination: methodology for philosophy of science. European Journal for Philosophy of Science 2(2).

Kauppinen, A. (2018, December). Agency, experience, and future bias. Thought: A Journal of Philosophy 7(4), 237-245.

Knobe, J. (2019). Philosophical intuitions are surprisingly robust across demographic differences. Epistemology \& Philosophy of Science. 2.

Knobe, J. and S. Nichols (2017). Experimental philosophy. In E. N. Zalta (Ed.), The Stanford Encyclopedia of Philosophy (Winter 2017 ed.). Metaphysics Research Lab, Stanford University. 
Koch, S. (2019, January). Carnapian explications, experimental philosophy, and fruitful concepts. Inquiry, 1-18.

Koch, S. (forthcoming). The externalist challenge to conceptual engineering. Synthese.

Kuntz, J. and J. Kuntz (2011). Surveying philosophers about philosophical intuition. Review of Philosophy and Psychology 2(4), 643-665.

Lehrer, K. (2000). Theory of Knowledge, Volume 42. Westview Press.

Lindauer, M. (2019, May). Experimental philosophy and the fruitfulness of normative concepts. Philosophical Studies.

Loeb, D. (2016). Max deutsch, the myth of the intuitive: Experimental philosophy and philosophical method, mit press, 2015, 194pp., isbn 9780262028950. Notre Dame Philosophical Reviews: An Electronic Journal.

Logins, A. (2018, December). Subjective unpossessed reasons. Thought: A Journal of Philosophy 7(4), 262-270.

Machery, E. (2017). Philosophy Within its Proper Bounds. Oxford University Press.

Machery, E. and S. Stich (2019). Demographic differences in philosophical intuition: A reply to joshua knobe. ms.

Nado, J. (2016). The intuition deniers. Philosophical Studies 173, 781-800.

Nado, J. (2019, September). Conceptual engineering via experimental philosophy. Inquiry, 1-21.

Noichl, M. (2019, October). Modeling the structure of recent philosophy. Synthese.

Parfit, D. (2011). On What Matters: Volume One. Oxford: Oxford University Press.

Perl, C. (2018, May). Empirical ignorance as defeating moral intuitions? a puzzle for rule consequentialists (and others). analysis 79(1), 62-72.

Pinder, M. (2019, April). Does experimental philosophy have a role to play in carnapian explication? Ratio 30(4), 443-461.

Pinder, M. (forthcoming, September). Conceptual engineering, metasemantic externalism and speaker-meaning. Mind (fzz069). 
Plunkett, D. and H. Cappelen (2020). A guided tour of conceptual engineering and conceptual ethics. In H. Cappelen, D. Plunkett, and A. Burgess (Eds.), Conceptual Engineering and Conceptual Ethics. Oxford University Press.

Prinzing, M. (2018, November). The revisionist's rubric: conceptual engineering and the discontinuity objection. Inquiry 61(8), 854-880.

Reuter, K., J. Sytsma, and M. Sienhold (2018, June). Putting pain in its proper place. analysis 79(1), 72-82.

Riggs, J. (forthcoming). Conceptual engineers shouldn't worry about semantic externalism. Inquiry.

Robinson, J. (2018, June). On being cruel to a chair. analysis 79(1), 83-91.

Roelofs, L. (2018, December). Why imagining requires content: A reply to a reply to an objection to radical enactive cognition. Thought: A Journal of Philosophy 7(4), 246-254.

Saemi, A. (2018, June). The intention principle and the doctrine of double effect. analysis 79(1), 91-99.

Schupbach, J. N. (2015). Experimental explication. Philosophy and Phenomenological Research, $\mathrm{n} / \mathrm{a}-\mathrm{n} / \mathrm{a}$.

Shepherd, J. and J. Justus (2015, April). X-phi and carnapian explication. Erkenntnis 80(2), 381-402.

Simchen, O. (2018, December). The hierarchy of fregean senses. Thought: A Journal of Philosophy 7(4), 255-261.

Simion, M. (2018, November). The 'should' in conceptual engineering. Inquiry 61(8), 914-928.

Thomasson, A. (2020). A pragmatic method for normative conceptual work. In A. Burgess, H. Cappelen, and D. Plunkett (Eds.), Conceptual Engineering and Conceptual Ethics. OUP.

Torregrossa, C. (ms). Experimental philosophy and conceptual engineering in aesthetics.

Weingart, S. B. (2015). Finding the history and philosophy of science. Erkenntnis 80(1).

Weisberg, J. (2017). Journal submission rates by gender: A look at the APA/BPA data.

Wiegmann, A. and M. R. Waldmann (2014). Transfer effects between moral dilemmas: A causal model theory. Cognition 131(1), 28 - 43. 